\title{
Direct costs of common osteoporotic fractures (Hip, Vertebral and Forearm) in Iran
}

\author{
Marziyeh Rajabi ${ }^{1}$, Afshin Ostovar ${ }^{2}$, Ali Akbari Sari ${ }^{1}$, Sayed Mahmoud Sajjadi-Jazi ${ }^{3,4}$, Noushin Fahimfar2*, \\ Bagher Larijani ${ }^{3}$ and Rajabali Daroudi ${ }^{1 *}$ (D)
}

\begin{abstract}
Background: Osteoporotic fractures impose significant costs on society. The objective of this study was to estimate the direct costs of the hip, vertebral, and forearm fractures in the first year after fracture incidence in Iran.

Methods: We surveyed a sample of 300 patients aged over 50 years with osteoporotic fractures (hip, vertebral, and forearm) admitted to four hospitals affiliated to Tehran University of Medical Sciences, Iran, during 2017 and were alive six months after the fracture. Inpatient cost data were obtained from the hospital patient records. Using a questionnaire, the data regarding outpatient costs were collected through a phone interview with patients at least six months after the fracture incidence. Direct medical and non-medical costs were estimated from a societal perspective. All costs were converted to the US dollar using the average exchange rate in 2017 (1USD = IRR 34,214)

Results: The mean \pm standard deviation (SD) age of the patient was $69.83 \pm 11.25$ years, and $68 \%$ were female. One hundred and seventeen (39\%) patients had hip fractures, 56 (18.67\%) patients had vertebral fractures, and 127 (42.33\%) ones had forearm fractures. The mean direct cost (medical and non-medical) during the year after hip, vertebral and forearm fractures were estimated at USD5,381, USD2,981, and USD1,209, respectively.

Conclusion: The direct cost of osteoporotic fracture in Iran is high. Our findings might be useful for the economic evaluation of preventive and treatment interventions for osteoporotic fractures as well as estimating the economic burden of osteoporotic fractures in Iran.
\end{abstract}

Keywords: Costs, Fracture, Osteoporosis, Quality of life

\section{Introduction}

Osteoporosis is a major public health problem through associated fragility fractures [1]. The worldwide prevalence of osteoporosis is estimated to be over 200 million and it contributes to about 9 million fractures each year [2]. In the United States, the prevalence of osteoporosis in people over the age of 50 was estimated to be about

\footnotetext{
*Correspondence: nfahimfar@sina.tums.ac.ir; rdaroudi@sina.tums.ac.ir ${ }^{1}$ Department of Health Management and Economics, School of Public Health, Tehran University of Medical Sciences, Poursina Ave, Tehran, Iran ${ }^{2}$ Osteoporosis Research Center, Endocrinology and Metabolism Clinical Sciences Institute, Tehran University of Medical Sciences, No.10-Jalale-Ale-Ahmad St, Chamran Hwy, P. O. Box: 14117-13119, Tehran, Iran Full list of author information is available at the end of the article
}

10.3 percent (10.2 million people) in 2010 , and over 1.5 million fractures per year are attributed to osteoporosis $[3,4]$. Based on a systematic review and meta-analysis study, the prevalence of osteoporosis was estimated at $17 \%(95 \%$ CI [13\%, 20\%]) in Iran [5].

The clinical significance of osteoporosis lies in the resulting fractures. The most common fractures caused by osteoporosis include hip, spinal, and forearm fractures [6]. The global incidence of hip fracture was estimated to be 2.7 million cases in 2010 [7]. The findings of a systematic literature review of hip fracture incidence studies showed that the age-standardized annual incidence of hip fractures in women (per 100,000) was between 2 in Nigeria and 574 in Denmark [8]. The incidence of hip fractures in women in Iran is estimated at about 400/per original author(s) and the source, provide a link to the Creative Commons licence, and indicate if changes were made. The images or other third party material in this article are included in the article's Creative Commons licence, unless indicated otherwise in a credit line to the material. If material is not included in the article's Creative Commons licence and your intended use is not permitted by statutory regulation or exceeds the permitted use, you will need to obtain permission directly from the copyright holder. To view a copy of this licence, visit http://creativecommons.org/licenses/by/4.0/. The Creative Commons Public Domain Dedication waiver (http://creativeco mmons.org/publicdomain/zero/1.0/) applies to the data made available in this article, unless otherwise stated in a credit line to the data. 
100,000 people [2]. The number of hip fractures was estimated to be 50,000 cases in 2006 , and according to predictions, it will reach 62,000 cases in 2020 [9]. Data on the incidence of other osteoporotic fractures are lacking in most of the countries in the world, especially in the low and middle-income countries [10,11].

Osteoporosis and its related fractures, in addition to their effects on people's quality of life, impose a significant economic burden on families and the health system [1]. Financial costs, reduced quality of life, and premature death are among the consequences of osteoporosis and osteoporotic fractures $[1,4]$. In the United States, the direct cost of osteoporosis in 2005 was estimated to be between $\$ 13.7$ billion and $\$ 20.3$ billion and according to forecasts, by 2025 , more than 3 million osteoporosis fractures will occur annually, costing $\$ 25.3$ billion $[12,13]$. In 2005 in China, the direct cost per patient with a hip fracture was estimated to be $\$ 3,600$. The cost of treating hip fractures in 2005 was about $\$ 1.5$ billion and is estimated to increase to $\$ 12.5$ billion by 2020 [14]. In 2009, the direct medical costs of hip fractures in Iran was estimated to be $\$ 28$ million, and it is predicted to increase to $\$ 250$ million by 2050 [9].

To the best of our knowledge, there is limited knowledge about the economic burden of osteoporosis and fragility fractures in Iran [15]. Therefore, this study aimed at calculating the direct medical and non-medical costs of common osteoporotic fractures during one year after the fracture in Iran, in total and by fracture type.

\section{Methods}

This was a cross-sectional descriptive study in which we calculated the direct medical and non-medical costs imposed on patients within one year after the common osteoporotic fractures.

Direct medical costs included costs of hospitalization, medications, diagnostic tests, physician visits, and diagnostic imaging. Direct non-medical costs included costs of travel for treatment, absenteeism, Informal Care and services, and Patient Time Cost.

\section{Study participants}

The study samples included patients visiting teaching hospitals affiliated to Tehran University of Medical Sciences (TUMS) in 2017 due to common fractures caused by osteoporosis, including hip, vertebral, and forearm fractures. Inclusion criteria were age $\geq 50$ years, the incident of hip, vertebral or forearm fragility fractures (based on ICD_10 code) in 2017, T-score $\leq-2.5$ standard deviation (SD) or fracture due to minor trauma, admission in four teaching hospitals affiliated to TUMS (including Shariati, Sina, Baharlo, Ziaeian hospitals), and surviving at least six months after the fracture incidence. The total number of patients was 476 , of whom 71 died, and another 105 were excluded due to unwillingness to participate in the study or incorrect telephone number. Finally, 300 patients participated in the study.

\section{Data collection}

Inpatient costs were extracted from hospital records. Outpatient costs were also collected using a questionnaire through telephone interviews with patients. Since outpatient costs occur after hospital discharge, interviews with patients were performed at least 6 months after the occurrence of fracture. In the case of patients unable to answer questions, a family member or caregiver was interviewed who had sufficient information.

The study questionnaire consisted of 4 main sections. The first section of the questionnaire was related to patients' demographic information, including age, gender, marital status, place of residence, education status, employment status, and health insurance coverage status. The second section of the questionnaire was related to clinical information and a history of osteoporosis and osteoporotic fractures. In the third section, questions related to resource consumption were asked to calculate direct medical expenses. In this part of the questionnaire, patients were asked what services they had received over the past six months due to osteoporosis and related fractures, as well as the number of times each service was used.

For this purpose, a list of services including physician visits, imaging services, medications, diagnostic tests, and rehabilitation services was provided, and patients were asked about the use of each service. The fourth section of the questionnaire was related to direct non-medical costs, and patients were asked about the number of trips, costs of each trip, costs of absenteeism, home care, complementary treatment expenses (such as supplementations), and cost of using equipment such as wheelchairs, cane, etc.

The questionnaire was designed based on previous studies and its validity was confirmed through interviews with clinicians and health economists. Also, a pilot study was conducted and the questionnaire was revised based on its result accordingly.

Details of methods used for calculating direct medical and non-medical expenses by cost items are presented in supplement Table S1.

\section{Data analysis}

Descriptive statistics, including mean, median, and standard deviation, were used to describe the data. To calculate the cost of services for each patient, the number of times each service was used was multiplied by the average price of that service. The price of services 
was extracted from the official price list for medical services in Iran, approved by the Supreme Insurance Council. Finally, the average annual cost per patient within one year after the fracture had occurred was calculated by the type of cost. Data were analyzed using Microsoft Excel 2013 and Stata software programs (Stata Corporation, College Station, TX). All costs were converted to the US dollar using the average exchange rate in 2017 $(1 \mathrm{USD}=\mathrm{IRR} 34,214)$.

\section{Results}

Overall, 300 patients (65\% female) with a mean (SD) age of $69.83(11.25)$ were included in the study with a total of $127(42.3 \%), 117$ (39\%), and 56 (17.3\%) forearm, hip and clinical vertebral fractures, respectively. Other characteristics are shown in Table 1.

The average direct medical costs during the first year after hip, clinical vertebral, and forearm fracture were estimated to be $\$ 3,029.67, \$ 2,316.59$, and $\$ 924.90$, respectively. In all three groups, inpatient costs accounted for the largest share of direct medical costs. The share of inpatient costs out of the total direct medical costs in the hip, vertebral, and forearm fracture patients were $78.88 \%$, $53.70 \%$, and $37.29 \%$, respectively (Fig. 1). Rehabilitation and medication costs were in subsequent rankings (see Table 2).
Direct non-medical costs are presented separately by the type of fracture in Table 3. The average direct nonmedical costs per patient in the hip, clinical vertebral, and forearm fracture were estimated to be $\$ 2,351.63$, $\$$ 664.18 , and $\$ 284.40$, respectively. In hip fractures, about $82 \%$ of direct non-medical costs were related to patient informal care (see Fig. 1).

The average direct costs (medical and non-medical) during the first year after the fracture were estimated to be $\$ 5,381.30$, $\$ 2,980.78$, and $\$ 1,209.30$ for hip, clinical vertebral, and forearm fractures, respectively (see Table 4). The shares of direct medical costs out of the total direct costs in the hip, clinical vertebral, and forearm fractures were $56.30 \%, 77.72 \%$, and $76.48 \%$, respectively (see Fig. 1).

\section{Discussion}

In this study, direct medical and non-medical costs of common fractures caused by osteoporosis, including hip, clinical vertebral, and forearm fractures, were calculated in 2017. The average direct medical costs during the first year after a hip, vertebral, and forearm fracture were estimated to be $\$ 3,030, \$ 2,317$, and $\$ 925$, respectively. The average direct non-medical costs per patient in the hip, vertebral, and forearm fractures were estimated to be $\$$ $2,352, \$ 664$, and $\$ 284$, respectively.

Table 1 Sociodemographic characteristics of the participants

\begin{tabular}{|c|c|c|c|c|c|c|c|c|}
\hline \multirow[t]{3}{*}{ Variables } & \multicolumn{8}{|c|}{ Type of fracture } \\
\hline & \multicolumn{2}{|l|}{ Hip } & \multicolumn{2}{|c|}{ Vertebra } & \multicolumn{2}{|c|}{ Forearm } & \multicolumn{2}{|l|}{ Total } \\
\hline & $\mathbf{n}$ & $\%$ & $\mathrm{n}$ & $\%$ & $\mathbf{n}$ & $\%$ & $\mathrm{n}$ & $\%$ \\
\hline \multicolumn{9}{|l|}{ Gender } \\
\hline Female & 76 & 64.96 & 34 & 60.71 & 94 & 74.02 & 204 & 68.00 \\
\hline Male & 41 & 35.04 & 22 & 39.29 & 33 & 25.98 & 96 & 32.00 \\
\hline \multicolumn{9}{|l|}{ marital status } \\
\hline Single & 3 & 2.56 & 2 & 3.57 & 1 & 0.79 & 6 & 2.00 \\
\hline Married & 53 & 45.3 & 34 & 60.72 & 79 & 62.2 & 166 & 55.33 \\
\hline Widow/divorced & 61 & 52.14 & 20 & 35.71 & 47 & 37.01 & 128 & 42.67 \\
\hline \multicolumn{9}{|l|}{ employment status } \\
\hline Employment & 6 & 5.13 & 2 & 3.57 & 9 & 7.09 & 17 & 5.67 \\
\hline Housekeeper & 57 & 48.72 & 26 & 46.44 & 82 & 64.57 & 165 & 55.00 \\
\hline No employment & 15 & 12.82 & 8 & 14.28 & 13 & 10.24 & 36 & 12.00 \\
\hline Retired & 39 & 33.33 & 20 & 35.71 & 23 & 18.11 & 82 & 27.33 \\
\hline \multicolumn{9}{|c|}{ Having basic health insurance } \\
\hline Yes & 116 & 99.15 & 50 & 89.29 & 119 & 93.70 & 285 & 95.00 \\
\hline \multirow[t]{2}{*}{ No } & 1 & 0.85 & 6 & 10.71 & 8 & 6.30 & 15 & 5.00 \\
\hline & Mean & SD & Mean & SD & Mean & SD & Mean & SD \\
\hline Age & 73.58 & 11.33 & 69.70 & 10.39 & 66.42 & 10.50 & 69.83 & 11.25 \\
\hline Years of education & 6.44 & 5.87 & 6.28 & 5.63 & 5.61 & 5.15 & 6.06 & 5.53 \\
\hline
\end{tabular}




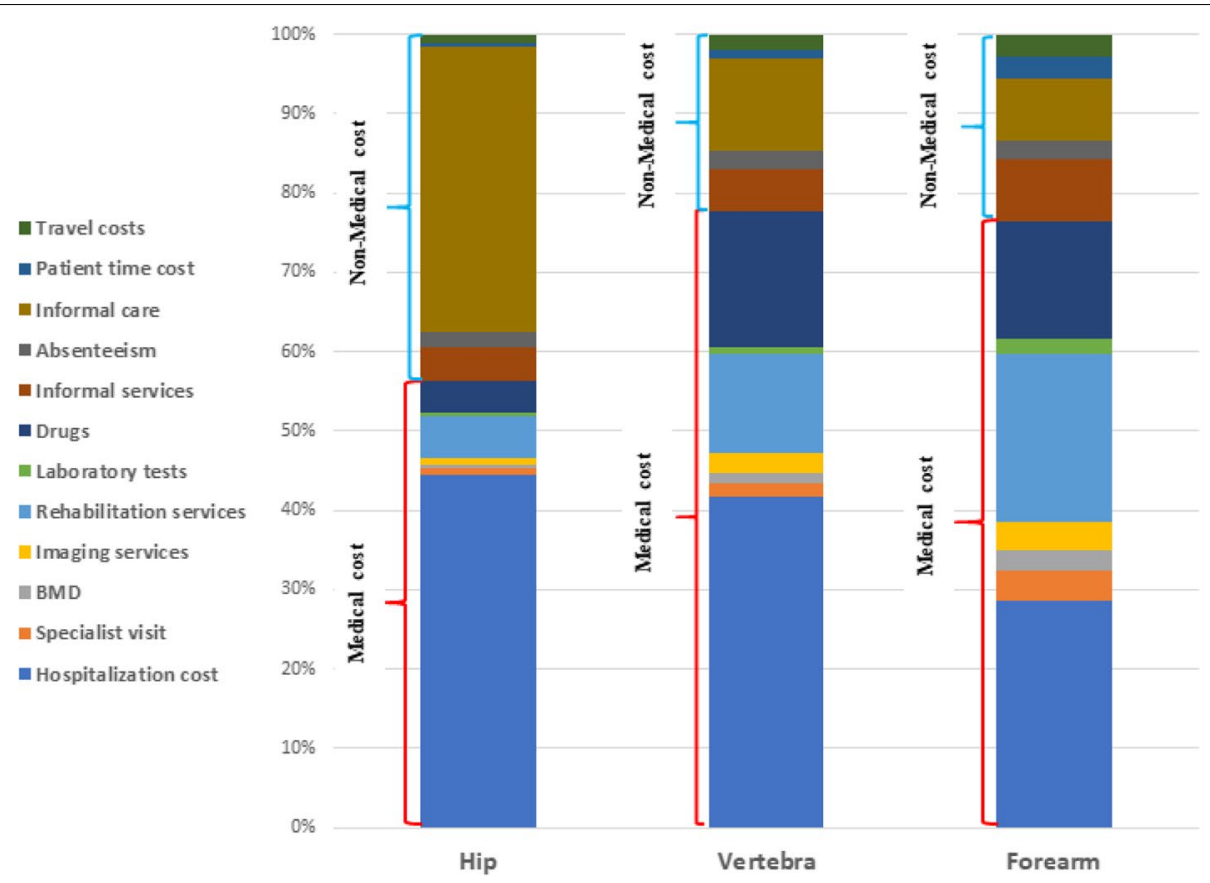

Fig. 1 Percentages of direct medical and non-medical costs of osteoporotic fracture by fracture type; BMD: Bone Mineral Density test

Table 2 Direct medical cost of osteoporotic fractures (per patient) during the year after the fracture

\begin{tabular}{|c|c|c|c|c|c|c|}
\hline \multirow[t]{3}{*}{ Cost Item } & \multicolumn{6}{|l|}{ Type of fracture } \\
\hline & \multicolumn{2}{|l|}{ Hip } & \multicolumn{2}{|l|}{ Vertebra } & \multicolumn{2}{|l|}{ Forearm } \\
\hline & Mean cost(US\$) & $\%$ of total & Mean cost(US\$) & $\%$ of total & Mean cost(US\$) & $\%$ of total \\
\hline Hospitalization cost & $2,389.65$ & 78.88 & $1,243.93$ & 53.70 & 344.88 & 37.29 \\
\hline Specialist visit & 45.85 & 1.51 & 49.41 & 2.13 & 47.56 & 5.14 \\
\hline $\mathrm{BMD}^{\mathrm{a}}$ test & 25.88 & 0.85 & 41.10 & 1.77 & 31.49 & 3.40 \\
\hline Imaging services $^{\mathrm{b}}$ & 50.13 & 1.65 & 72.26 & 3.12 & 42.22 & 4.56 \\
\hline Rehabilitation services & 282.49 & 9.32 & 371.24 & 16.03 & 254.82 & 27.55 \\
\hline Laboratory tests & 24.55 & 0.81 & 26.86 & 1.16 & 25.19 & 2.72 \\
\hline Drugs $^{c}$ & 211.11 & 6.97 & 511.81 & 22.09 & 178.75 & 19.33 \\
\hline Total & $3,029.67$ & 100.00 & $2,316.59$ & 100.00 & 924.90 & 100.00 \\
\hline
\end{tabular}

${ }^{a}$ Bone Mineral Density; ${ }^{b}$ (MRI, CT-SCAN); ${ }^{c}$ (osteoporosis drug and painkillers)

One of the most common osteoporotic fractures is the hip fracture, which impose heavy economic and social burdens on families and communities. It has been estimated that $8-36 \%$ of people with hip fractures die within a year of the fracture incidence [16], and 20-30\% of these deaths are directly attributed to hip fractures [17]. Only $40-60 \%$ of patients return to pre-fracture mobility, and $20-60 \%$ of patients who perform personal activities such as washing and dressing without assistance before the fracture are unable to do so alone for more than one year after the fracture. In high-income countries, between
10-20\% of patients require long-term care after a hip fracture $[18,19]$.

Almost all patients with hip fractures are hospitalized. Their length of stay in the hospital is relatively long, and most of them need home care after hospital discharge $[18,20]$. The total cost estimated in our study for hip fracture was $\$ 5,381$. According to a systematic review, the average hospital cost per patient with hip fracture in the United States was between \$ 8,358 and \$ 32,195, with the highest hospital cost among osteoporotic fractures [21]. The results of a more recent study in the United States 
Table 3 Direct non-medical cost of osteoporotic fractures (per patient) during the year after the fracture

\begin{tabular}{|c|c|c|c|c|c|c|}
\hline \multirow[t]{3}{*}{ Cost Item } & \multicolumn{6}{|l|}{ Type of fracture } \\
\hline & \multicolumn{2}{|l|}{ Hip } & \multicolumn{2}{|l|}{ Vertebra } & \multicolumn{2}{|l|}{ Forearm } \\
\hline & Mean cost(US\$) & $\%$ of total & Mean cost(US\$) & $\%$ of total & Mean cost(US\$) & $\%$ of total \\
\hline $\begin{array}{l}\text { Informal services (including supplements, } \\
\text { Walker, cane, and ...) }\end{array}$ & 224.38 & 9.54 & 160.42 & 24.15 & 95.22 & 33.48 \\
\hline Absenteeism ( by patient and family members) & 109.22 & 4.64 & 69.37 & 10.44 & 26.35 & 9.27 \\
\hline Informal care & $1,929.02$ & 82.03 & 344.52 & 51.87 & 96.45 & 33.91 \\
\hline Patient time cost & 30.54 & 1.30 & 31.41 & 4.73 & 31.31 & 11.01 \\
\hline Travel costs & 58.46 & 2.49 & 58.46 & 8.80 & 35.07 & 12.33 \\
\hline Total & $2,351.63$ & 100.00 & 664.18 & 100.00 & 284.40 & 100.00 \\
\hline
\end{tabular}

Table 4 Direct cost (medical and non-medical) of osteoporotic fractures (per patient) during the year after the fracture

\begin{tabular}{|c|c|c|c|c|c|c|}
\hline \multirow[t]{3}{*}{ Cost Item } & \multicolumn{6}{|l|}{ Type of fracture } \\
\hline & \multicolumn{2}{|l|}{ Hip } & \multicolumn{2}{|l|}{ Vertebra } & \multicolumn{2}{|l|}{ Forearm } \\
\hline & Mean cost(US\$) & $\%$ of total & Mean cost(US\$) & $\%$ of total & Mean cost(US\$) & $\%$ of total \\
\hline Direct medical cost & $3,029.67$ & 56.30 & $2,316.59$ & 77.72 & 924.90 & 76.48 \\
\hline Direct non-medical cost & $2,351.63$ & 43.70 & 664.18 & 22.28 & 284.40 & 23.52 \\
\hline Total cost & $5,381.30$ & 100.00 & $2,980.78$ & 100.00 & $1,209.30$ & 100.00 \\
\hline
\end{tabular}

also showed that the average length of hospital stay for a patient with hip fracture was 5.6 days and the average hospital cost was $\$ 14,744$ [22]. The results of a study in the UK demonstrated that the average hospital costs for hip fractures during the first and second years after fracture were $£ 14,163$ and $£ 2,139$, respectively [23]. According to a systematic review and meta-analysis conducted by Williamson et al., the average hospital cost for a hip fracture was $\$ 10,075$ (95\% CI [ $\$ 8,322, \$ 11,828]$ ) globally [24].

One study conducted by Wiktorowicz et al. revealed that primary hospital costs account for about one-third of total patient medical costs during the first year after a hip fracture, and about $70 \%$ of the costs during the first year are related to informal care, as well as rehabilitation and other outpatient services [25]. According to the above study, the average health and social cost of a hip fracture during the first year after the fracture was $\$ 43,669$ per patient. The average cost of hospitalization per patient was $\$ 13,331$, accounting for about $74 \%$ of total medical care costs. Rehabilitation and medication costs, with about $35 \%$ and $8 \%$, respectively, were in the next ranks [24]. In our study, hospital costs accounted for about $79 \%$ of direct medical costs of hip fractures, and rehabilitation and medication costs were 9\% and $7 \%$, respectively. A comparison of our findings with that of others suggest that the share of rehabilitation service costs in our study was lower than in other studies. one reason for this could be the low coverage of rehabilitation services by health insurance in Iran and less use of these services by patients.

Mohd-Tahir et al. conducted a review study in 2017 to estimate the costs of osteoporotic hip fractures in Asian countries. The results of their research showed that few studies had been published on the costs of hip fractures in Asian countries. Only 15 studies had met the criteria for entering in the study. Studies also differed in terms of methodology and type of costs estimated; and most studies have only estimated direct medical costs. According to the so called study, the average cost of a hip fracture in Asia ranged from $\$ 774$ to $\$ 14,199$, with a median cost of $\$ 2,944$ [26]. In our study, the average direct cost of a hip fracture was estimated to be $\$ 3,030$, which is close to the estimated median in Asian countries.

Vertebral fractures are another common osteoporotic fracture that, like hip fractures, increase the risk of death and impose high costs on patients [27]. Ong et al. conducted a systematic review to evaluate the characteristics and outcomes of hospitalized patients due to vertebral fractures. Their study results showed that the rate of hospital admissions due to vertebral fractures in different countries was between 2.8 to 19.3 per 10,000 people per year. The ratio of women to men in different studies was between 57 and $84 \%$ with the average of $65 \%$ in all studies. Between 20 and $27 \%$ of patients died within the first year after the fracture. Also, they found that after hospital 
discharge, between 34 and $50 \%$ of patients were referred to other patient care centers, such as nursing homes, and 24-38\% were discharged without the need for formal care, in addition 11-15\% were discharged with formal care. The median length of stay was 9.8 [28]. According to the study of Weycker et al., the average length of hospital stay for patients with vertebral fractures in the United States was 5.4 days, and the average hospital cost per patient was \$ 11,681 [22].

Among osteoporotic fractures, forearm fractures have almost the lowest cost compared to other fractures. Hospital costs for wrist / forearm fractures in the United States ranged from $\$ 1,885$ to $\$ 12,136$, compared to $\$$ 6,346 to $\$ 11,236$ for vertebral fractures and $\$ 8,355$ to $\$ 32,195$ for hip fractures [21]. In the study of Hernlund et al., the average cost of the hip, vertebral, and forearm fractures one year after fracture in European countries was estimated to be $€ 13,816$, $€ 3380$, and $€ 989$, respectively [10]. In a Chinese study, the average cost of fractures in these common sites during the first year after a fracture was estimated to be $\$ 4,330, \$ 3,409$, and $\$ 1,401$, respectively [29]. These costs in our study were estimated at $\$ 5,381.30, \$ 2,980.78$, and $\$ 1,209.30$, respectively, which is almost close to the estimated costs in China.

On the basis of the findings of this study and those of other reports, osteoporotic fractures impose a high financial burden on society [10]. There are currently several interventions such as pharmacotherapy and lifestyle modification that are effective and cost-effective in preventing fractures [30, 31]. However, osteoporosis and its related fractures has largely remained globally as an underdiagnose and undertreated health issue [32, 33]. Untreated osteoporosis increases the risk of further fragility fractures [33]. Therefore, eliminating barriers to timely diagnosis and treatment of osteoporosis will lead to fracture prevention.

To the best of our knowledge, this is the first study to estimate the cost within the first year after the common osteoporotic fractures in Iran. However, our study has some limitations. The data were collected from hospitalized patients; therefore, the estimated costs of this study may not be generalizable to non-hospitalized patients. In the case of hip fractures, almost all patients are hospitalized, so our results can be generalized to all of these patients. In the case of vertebral and forearm fractures, according to previous studies, about $35 \%$ of vertebral fractures and $25 \%$ of forearm fractures require hospitalization [34,35]. Thus, our estimates for the cost of vertebral and forearm fractures are limited to patients who are admitted to hospital.

Furthermore, in this study, we excluded the patients who died within six months after the fracture. As patients who died after fracture are more severe and could incur higher hospital costs (particularly for hip fracture), excluding them may result in underestimation of the hospitalization costs.

Moreover, outpatient costs in Iran are recorded in multiple databases. Taking this into account that some of the out of pockets costs are not recorded anywhere, so the results of the study might be affected by the recall bias since the outpatient costs were estimated through patients' interviews.

\section{Conclusion}

Our study showed that common fractures caused by osteoporosis in Iran impose significant costs on patients and society. Due to the increase in life expectancy and the percentage of the elderly population, the incidence and prevalence of osteoporosis and related fractures are increasing that results in higher costs in the future. Implementing cost-effective interventions is necessary to prevent osteoporotic fractures and reduce their associated costs.

\section{Abbreviations}

CT: Computed tomography; MRI: Magnetic resonance imaging; BMD: Bone Mineral Density; TUMS: Tehran University of Medical Sciences.

\section{Supplementary Information}

The online version contains supplementary material available at https://doi. org/10.1186/s12891-021-04535-8.

Additional file 1: Table S1. Methods of measuring direct medical and non-medical costs in this study.

\section{Acknowledgements}

We thank the managers and staff at the Shariati, Sina, Baharlo, Ziaeian hospitals for their assistance in conducting this research.

\section{Authors' contributions}

All authors contributed to the study's conception and design. Material preparation, data collection, and analysis were performed by RD, MR, AO, AS, SMS-J, $N F$, and BL. The first draft of the manuscript was written by RD and MR and all authors commented on previous versions of the manuscript. All authors read and approved the final manuscript.

\section{Funding}

This study was funded by the Tehran University of Medical Sciences (grant number 9611119004).

\section{Availability of data and materials}

The datasets used and/or analyzed during the current study are available from the corresponding author on reasonable request.

\section{Declarations}

\section{Ethics approval and consent to participate}

This study was approved by the ethics committee of the Deputy of Research and Technology of the Tehran University of Medical Sciences (IR.TUMS.EMRI. REC.1396.0016). All authors confirm and declare that this study was conducted in compliance with the Declaration of Helsinki. The participants were assured 
that their information would remain confidential. Informed consent was obtained from all individual participants included in the study.

\section{Consent for publication}

Not applicable.

\section{Competing interests}

Marzieh Rajabi, Afshin Ostovar, Ali Akbari Sari, Sayed Mahmoud Sajjadi-Jazi, Noushin Fahimfar, Bagher Larijani, and Rajabali Daroudi declare that they have no conflict of interest.

\section{Author details}

${ }^{1}$ Department of Health Management and Economics, School of Public Health, Tehran University of Medical Sciences, Poursina Ave, Tehran, Iran. ${ }^{2}$ Osteoporosis Research Center, Endocrinology and Metabolism Clinical Sciences Institute, Tehran University of Medical Sciences, No.10-Jalal-e-Ale-Ahmad St, Chamran Hwy, P. O. Box: 14117-13119, Tehran, Iran. ${ }^{3}$ Endocrinology and Metabolism Research Center, Endocrinology and Metabolism Clinical Sciences Institute, Tehran University of Medical Sciences, Tehran, Iran. ${ }^{4}$ Cell Therapy and Regenerative Medicine Research Center, Endocrinology and Metabolism Molecular-Cellular Sciences Institute, Tehran University of Medical Sciences, Tehran, Iran.

Received: 23 April 2021 Accepted: 15 July 2021

Published online: 31 July 2021

\section{References}

1. Häussler B, Gothe H, Göl D, Glaeske G, Pientka L, Felsenberg D. Epidemiology, treatment and costs of osteoporosis in Germany - the BoneEVA Study. Osteoporosis Int. 2007;18(1):77-84.

2. Cooper C, Ferrari SL. IOF compendium of osteoporosis, IOF Board and Executive Committee. 2017. From https://archiveouverte.unige.ch/unige: 125569.

3. Wright NC, Looker AC, Saag KG, Curtis JR, Delzell ES, Randall S, et al. The recent prevalence of osteoporosis and low bone mass in the United States based on bone mineral density at the femoral neck or lumbar spine. J Bone Mineral Res. 2014;29(11):2520-6.

4. Blume SW, Curtis JR. Medical costs of osteoporosis in the elderly Medicare population. Osteoporosis Int. 2011;22(6):1835-44.

5. Irani AD, Poorolajal J, Khalilian A, Esmailnasab N, Cheraghi Z. Prevalence of osteoporosis in Iran: A meta-analysis. J Res Med Sci. 2013;18(9):759.

6. Cooper C, Dennison EM, Leufkens HG, Bishop N, van Staa TP. Epidemiology of childhood fractures in Britain: a study using the general practice research database. J Bone Mineral Res. 2004;19(12):1976-81.

7. Odén A, McCloskey EV, Johansson H, Kanis JA. Assessing the impact of osteoporosis on the burden of hip fractures. Calcified Tissue Int 2013;92(1):42-9.

8. Kanis JA, Oden A, McCloskey EV, Johansson H, Wahl DA, Cooper C. A systematic review of hip fracture incidence and probability of fracture worldwide. Osteoporosis Int. 2012;23(9):2239-56.

9. Ahmadi-Abhari S, Moayyeri A, Abolhassani F. Burden of hip fracture in Iran. Calcified Tissue Int. 2007;80(3):147-53.

10. Hernlund E, Svedbom A, Ivergård M, Compston J, Cooper C, Stenmark J, et al. Osteoporosis in the European Union: medical management, epidemiology and economic burden. Arch Osteoporosis. 2013;8(1-2):136.

11. Ballane G, Cauley J, Luckey M, Fuleihan GE-H. Worldwide prevalence and incidence of osteoporotic vertebral fractures. Osteoporosis Int. 2017;28(5):1531-42

12. Burge R, Dawson-Hughes B, Solomon DH, Wong JB, King A, Tosteson A. Incidence and economic burden of osteoporosis-related fractures in the United States, 2005-2025. J Bone Mineral Res. 2007;22(3):465-75.

13. Roche J, Wenn RT, Sahota O, Moran CG. Effect of comorbidities and postoperative complications on mortality after hip fracture in elderly people: prospective observational cohort study. BMJ. 2005;331(7529):1374.

14. Luo L, Xu L. Analysis of direct economic burden of osteoporotic hip fracture and its influence factors. Chin J Epidemiol. 2005;9:9.
15. Alipour V, Meshkani Z, Rezapour A, Aboutorabi A, Bagherzadeh R, Saber N. Medical costs of osteoporosis in the Iranian elderly patients. Med J Islamic Republic Iran. 2020;34:37.

16. Abrahamsen B, van Staa T, Ariely R, Olson M, Cooper C. Excess mortality following hip fracture: a systematic epidemiological review. Osteoporosis Int. 2009;20(10):1633-50.

17. Rapp K, Büchele G, Dreinhöfer K, Bücking B, Becker C, Benzinger P. Epidemiology of hip fractures. Z Gerontol Geriatr. 2019;52(1):10-6.

18. Dyer SM, Crotty M, Fairhall N, Magaziner J, Beaupre LA, Cameron ID, et al. A critical review of the long-term disability outcomes following hip fracture. BMC Geriatr. 2016;16(1):158.

19. Magaziner J, Hawkes W, Hebel JR, Zimmerman SI, Fox KM, Dolan M, et al. Recovery from hip fracture in eight areas of function. J Gerontol Ser A Biol Sci Med Sci. 2000;55(9):M498-507.

20. Nazrun AS, Tzar MN, Mokhtar SA, Mohamed IN. A systematic review of the outcomes of osteoporotic fracture patients after hospital discharge: morbidity, subsequent fractures, and mortality. Ther Clin Risk Manage. 2014;10:937.

21. Budhia S, Mikyas Y, Tang M, Badamgarav E. Osteoporotic fractures. Pharmacoeconomics. 2012;30(2):147-70

22. Weycker D, Li X, Barron R, Bornheimer R, Chandler D. Hospitalizations for osteoporosis-related fractures: Economic costs and clinical outcomes. Bone Rep. 2016:5:186-91.

23. Leal J, Gray A, Prieto-Alhambra D, Arden NK, Cooper C, Javaid MK, et al. Impact of hip fracture on hospital care costs: a population-based study. Osteoporosis Int. 2016;27(2):549-58.

24. Williamson S, Landeiro F, McConnell T, Fulford-Smith L, Javaid MK, Judge A, et al. Costs of fragility hip fractures globally: a systematic review and meta-regression analysis. Osteoporosis Int. 2017;28(10):2791-800.

25. Wiktorowicz M, Goeree R, Papaioannou A, Adachi JD, Papadimitropoulos E. Economic implications of hip fracture: health service use, institutional care and cost in Canada. Osteoporosis Int. 2001;12(4):271-8.

26. Mohd-Tahir N, Li S. Economic burden of osteoporosis-related hip fracture in Asia: a systematic review. Osteoporosis Int. 2017;28(7):2035-44.

27. Lange A, Zeidler J, Braun S. One-year disease-related health care costs of incident vertebral fractures in osteoporotic patients. Osteoporosis Int. 2014;25(10):2435-43.

28. Ong T, Kantachuvesiri P, Sahota O, Gladman JR. Characteristics and outcomes of hospitalised patients with vertebral fragility fractures: a systematic review. Age Ageing. 2018;47(1):17-25.

29. Qu B, Ma Y, Yan M, Wu H-H, Fan L, Liao D-F, et al. The economic burden of fracture patients with osteoporosis in western China. Osteoporosis Int. 2014;25(7):1853-60

30. Si L, Winzenberg T, Palmer A. A systematic review of models used in costeffectiveness analyses of preventing osteoporotic fractures. Osteoporosis Int. 2014;25(1):51-60.

31. Saito T, Sterbenz J, Malay S, Zhong L, MacEachern M, Chung K. Effectiveness of anti-osteoporotic drugs to prevent secondary fragility fractures: systematic review and meta-analysis. Osteoporosis Int. 2017;28(12):3289-300.

32. Pepe J, Agosti P, Cipriani C, Tettamanti M, Nobili A, Colangelo L, et al. Underdiagnosis and undertreatment of osteoporotic patients admitted in internal medicine wards in Italy between 2010 and 2016 (the REPOSI Register). Endocrine. 2021;71(2):484-93.

33. Iolascon G, Moretti A, Toro G, Gimigliano F, Liguori S, Paoletta M. Pharmacological therapy of osteoporosis: what's new? Clin Interv Aging. 2020;15:485.

34. Borgström F, Sobocki P, Ström O, Jönsson B. The societal burden of osteoporosis in Sweden. Bone. 2007;40(6):1602-9.

35. Saeb M, Beyranvand M, Basiri Z, Haghparast-Bidgoli H. The hospital resource utilization associated with osteoporotic hip fractures in Kermanshah. Iran J Injury Violence Res. 2014;6(1):16.

\section{Publisher's Note}

Springer Nature remains neutral with regard to jurisdictional claims in published maps and institutional affiliations. 